\title{
Dose Response Relationship of Nuclear Changes with Fractionated Radiotherapy in Assessing Radiosensitivity of Oral Squamous Cell Carcinoma
}

\author{
Vineet Raj ${ }^{1}$, Sumita Mahajan ${ }^{2}$. \\ ${ }^{1}$ M.D.S. Senior Lecturer. Department of Oral and Maxillofacial Pathology. Saraswati Dental College \& Hospital. Lucknow, \\ India. \\ ${ }^{2}$ M.D.S. Erstwhile Professor and Head. Department of Oral Pathology and Microbiology. Manipal College of Dental Sciences. \\ Mangalore, India.
}

Correspondence:

Flat No. 402, Rohtas Vintage Apartment,

29, Jopling Road,

Lucknow-226001

Uttar Pradesh, India.

E-mail:vineetraj@yahoo.com

Received: $29 / 11 / 2010$

Accepted: 28/02/2011
Raj V, Mahajan S. Dose Response Relationship of Nuclear Changes with Fractionated Radiotherapy in Assessing Radiosensitivity of Oral Squamous Cell Carcinoma. J Clin Exp Dent. 2011;3(3):e193-200. http://www.medicinaoral.com/odo/volumenes/v3i3/jcedv3i3p193.pdf

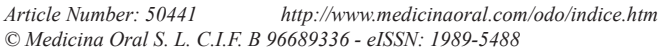

\begin{abstract}
Radiotherapy is frequently used as treatment for oral cancer either alone or in combination with surgery. Reaction of tumor tissue to radiotherapy often shows marked inter-individual variability making it difficult to assess and predict the treatment outcome for individual patients. Recently attention has been drawn towards the role of radiation induced nuclear changes to assess radiosensitivity.

Objectives: To establish the relationship between various nuclear changes with radiation dose and to explore the possibility of utilizing them as an assay to predict tumor response to radiotherapy.

Study Design: Study group consisted of 20 patients with histologically proven oral squamous cell carcinoma treated by fractionated radiotherapy, receiving a total of $60 \mathrm{~Gy}$ of external beam radiation in 30 fractions of 2 Gy each given daily. Serial scrape smears were collected from the lesion and contralateral normal site before the start of treatment and after 4th, 8th, and 12th fraction. Staining with acridine orange fluorescent dye and May-Grunwald Giemsa stain was done to assess nuclear abnormalities like micronucleation, nuclear budding, binucleation, and multinucleation. These were then correlated with tumor response.

Results: Statistically significant dose related increase in all nuclear abnormalities was observed with micronucleation being the most reliable independent parameter for assessing radiation induced damage of cancer cells. Nuclear abnormalities were significantly higher in lesional tissue than normal but did not show statistically significant correlation with tumor response though there was a trend towards higher counts in patients with good tumor response.

Conlusion: A direct dose-response relationship exists between the frequencies of various nuclear abnormalities and radiation exists in oral squamous cell carcinoma patients undergoing fractionated radiotherapy. Further studies are required to improve the understanding of the role of these changes in predicting tumor radiosensitivity.
\end{abstract}

Key Words: Micronucleus, Nuclear anomalies, Fractionated radiotherapy, Radiosensitivity, Oral squamous cell carcinoma 


\section{Introduction}

Cancer of oral cavity is one of the most common cancers in the world and is a major cause of morbidity and mortality. Developing countries have the world's highest reported incidence of oral cancer with squamous cell carcinoma being the most common histological type. Radiotherapy is frequently used as a standard treatment for carcinoma of the oral cavity either alone or in combination with surgery.(1) The reaction of tumor tissue, as well as the surrounding oral tissues, to radiotherapy depends on their growth rate and inherent susceptibility to radiation, which often shows a marked inter-individual variability making it difficult to assess and predict the outcome of the treatment for individual patients. The estimation of radiosensitivity of individual tumors will be essential not only in choosing the treatment, but also for planning the optimum radiation schedule for each patient.

Efforts to develop tests which could predict the response of tumor to radiotherapy in an individual patient have been made in past and are still being pursued. Early investigators used biopsies from the lesional site in order to predict response to radiotherapy.(2) Later Graham pioneered the use of exfoliative cytology to assess radiation related changes in cervical cancer and found them useful in predicting response to the treatment.(2) Graham's radiation response (RR) test, though reproduced by some later studies, was not universally accepted as an indicator for treatment outcome.(3) Nucleoprotein patterns of irradiated malignant exfoliated cells as well as persistence of malignant cells in smears after completion of therapy were also proposed to correlate with clinical outcome.(4) Recently attention has been drawn towards the role of radiation induced acute nuclear changes as an assay to assess radiosensitivity.(5-11) In past micronucleus has been recommended as an "internal biologic dosimeter" for radiation exposure(12) and some studies have shown it to be a reliable indicator of radiosensitivity of tumors.(13)

The current pilot study was undertaken to establish the relationship between various nuclear changes with radiation dose and to explore the possibility of utilizing them as an assay to predict tumor response to radiotherapy.

\section{Material and Methods}

The study was conducted in the Department of Oral Pathology and Microbiology, Manipal College of Dental Sciences, Mangalore, India. The study group consisted of 20 patients with histologically proven squamous cell carcinoma of oral cavity treated by radical radiotherapy alone at the Department of Oncology \& Radiotherapy, Kasturba Medical College Hospital, Mangalore. Each patient received a total of $60 \mathrm{~Gy}$ of external beam radiation in 30 fractions of 2 Gy each given daily, five times a week, over a period of six weeks. Only those patients who satisfied the above criteria and were followed up for at least one month post therapy were included in the study. Any patient treated with other modalities, like surgery or/and chemotherapy, in conjunction with radiotherapy or with radiation schedules different from the above mentioned were excluded from the study. Patients with tumors in inaccessible areas from where a proper smear collection was not feasible or patients who did not had a follow-up of at least one month post treatment were also excluded.

Complete case history and clinical findings of each patient were recorded after a thorough examination of the oral cavity. Pretreatment scrape smears were collected from each patient before the start of the treatment for baseline information. Two scrapings each [one for acridine orange (AO) fluorescent staining and the other for staining with May-Grunwald Geimsa (MGG) stain] were made from the lesion as well as contralateral apparently normal appearing mucosa. For ulcerated lesions the scrapings were made from the edge of the ulcer, taking care to avoid necrotic areas and slough. Subsequently three more scrape smears were taken from the same sites after delivery of 8, 16, 24 Gy of radiation. Smears were not collected after 24 Gy because radiation mucositis made it difficult to clinically differentiate the margins of tumor from normal tissue. Scrapings were made with the help of a sterile wooden spatula moistened in distilled water. The obtained material was immediately smeared on a grease free glass slide. Smears to be stained with AO stain were immediately fixed in equal volume of ether and alcohol, while those to be stained with MGG stain were air dried and then fixed in methyl alcohol.

A total of five hundred random epithelial cells were counted in each smear from the affected and unaffected site of each patient and the results were expressed as number of cells showing nuclear abnormality per 1000 cells. Poorly preserved cells, cell clumps, and cells with indistinct or disintegrated nuclear membrane were not counted.

Four types of nuclear changes were evaluated and the criteria used for identification of the same were as follows:

Micronucleation: intra-cytoplasmic, DNA staining bodies found in the same plane as the main nucleus with same or slightly lesser staining intensity, less than onethird the size the main nucleus, placed within two nuclear diameters from the main nucleus but distinctly separate from it (Fig 1a, 2a).

Nuclear budding: bodies similar to micronuclei except for the fact that their separation from the main nucleus was indistinct (Fig 1b, 2b).

Binucleation: two nuclei in a single cell with no micronucleus or nuclear budding (Fig 1c, 2c).

Multinucleation: more than two nuclei in a single cell with no micronucleus or nuclear budding (Fig 1d, 2d). 


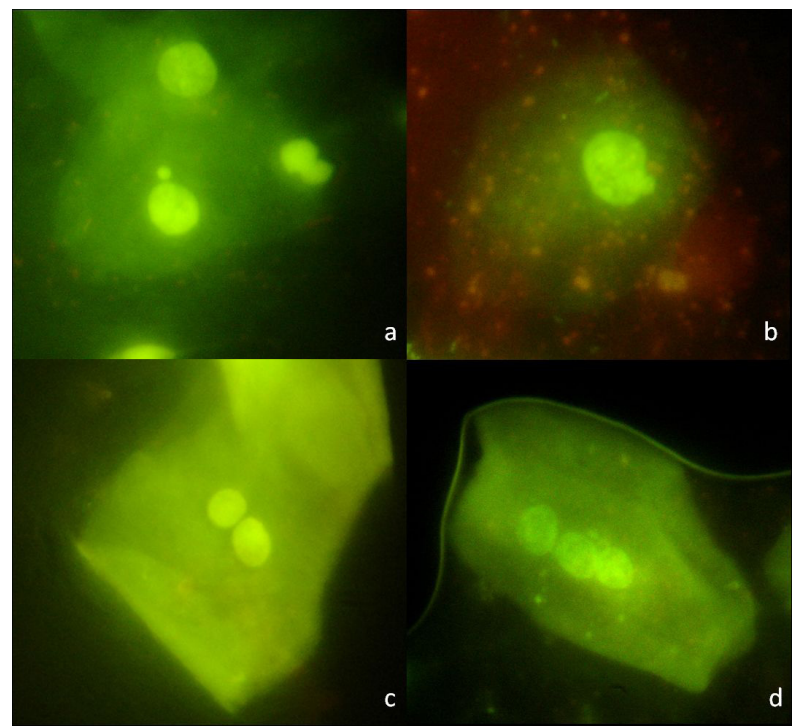

Fig. 1. shows various radiation induced nuclear abnormalities in fluorescent microscopy (a) micronucleus; (b) nuclear budding; (c) binucleation; (d) multinucleation. (Acridine Orange stain, 100 X)

In addition to analyzing the above parameters individually, total number of cells showing nuclear abnormalities was also calculated by computing the sum of all the cells showing any of the above parameters. This was considered as a separate parameter and named abnormally nucleated cells (ANC).

One month after the end of treatment the patients were examined for primary tumor response based on the reduction in tumor size which was calculated by comparing the maximum diameter of the lesion with the maximum diameter at the start of the treatment. Depending on this the patients were divided into three categories:

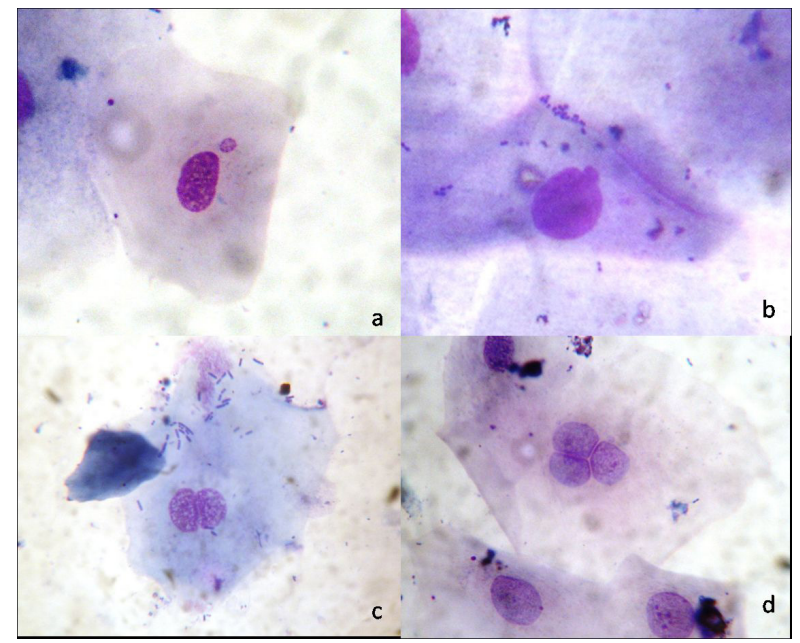

Fig. 2. shows various radiation induced nuclear abnormalities in conventional bright field microscopy (a) micronucleus; (b) nuclear budding; (c) binucleation; (d) multinucleation. (May Grunwald Geimsa stain, 100 X)

Good response: No evidence of primary tumor. Partial response: Reduction in the size of tumor by $50 \%$ or more.

Poor response: Less than $50 \%$ reduction in the size of tumor or progressive primary lesion.

The tumor response was then correlated with the various parameters evaluated and the results thus obtained were subjected to statistical analysis using Mann Whitney ' $U$ ' test, Kruskal Wallis test, and Wilcoxon signed rank sum test. Statistical package SPSS version 11.0 software was used for the statistical analysis. A $p$ value of 0.05 or less was considered to be statistically significant.
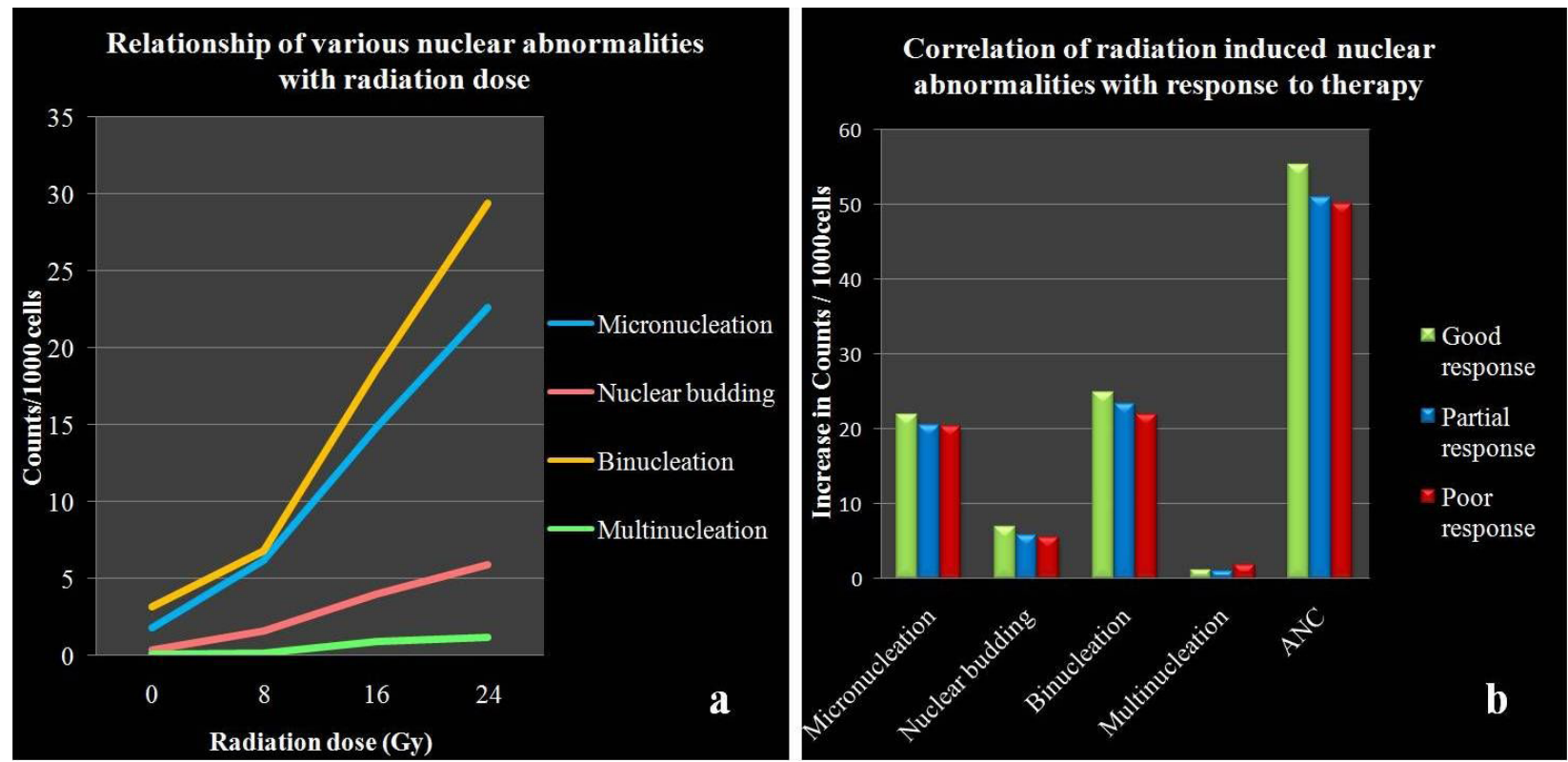

Fig. 3. (a) shows change in the counts of various nuclear abnormalities with increasing radiation dose; (b) shows the relationship of nuclear parameters with response to radiotherapy. 


\begin{tabular}{|c|c|c|c|c|c|c|}
\hline \multirow[t]{2}{*}{ Parameter } & \multirow[t]{2}{*}{ Site } & & \multicolumn{4}{|c|}{ Dose of radiation } \\
\hline & & & Baseline & 8 Gy & 16 Gy & 24 Gy \\
\hline \multirow{2}{*}{$\begin{array}{l}\text { Micro- } \\
\text { nucleus }\end{array}$} & $\mathbf{N}$ & $\begin{array}{c}\text { Mean } \pm \text { S.D. } \\
Z(\mathrm{p})\end{array}$ & $0.9 \pm 1.373$ & $\begin{array}{c}3.6 \pm 2.563 \\
3.143(\mathbf{0 . 0 0 1})\end{array}$ & $\begin{array}{c}11.5 \pm 2.563 \\
3.939(\mathbf{0 . 0 0 1})\end{array}$ & $\begin{array}{c}19.2 \pm 2.563 \\
3.941(\mathbf{0 . 0 0 1})\end{array}$ \\
\hline & $\mathbf{L}$ & $\begin{array}{c}\text { Mean } \pm \text { S.D. } \\
Z(p)\end{array}$ & $1.8 \pm 1.576$ & $\begin{array}{c}6.2 \pm 4.047 \\
3.712(\mathbf{0 . 0 0 1})\end{array}$ & $\begin{array}{c}14.8 \pm 3.750 \\
3.935(\mathbf{0 . 0 0 1})\end{array}$ & $\begin{array}{c}22.6 \pm 4.260 \\
3.943(\mathbf{0 . 0 0 1})\end{array}$ \\
\hline \multirow{2}{*}{$\begin{array}{l}\text { Nuclear } \\
\text { budding }\end{array}$} & $\mathbf{N}$ & $\begin{array}{c}\text { Mean } \pm \text { S.D. } \\
Z(p)\end{array}$ & $0.6 \pm 1.142$ & $\begin{array}{c}0.7 \pm 1.174 \\
0.333(0.748) \\
\end{array}$ & $\begin{array}{c}2.8 \pm 2.093 \\
3.131(\mathbf{0 . 0 0 1}) \\
\end{array}$ & $\begin{array}{c}5.0 \pm 3.078 \\
3.868(\mathbf{0 . 0 0 1 )} \\
\end{array}$ \\
\hline & $\mathbf{L}$ & $\begin{array}{c}\text { Mean } \pm \text { S.D. } \\
Z(p)\end{array}$ & $0.4 \pm 1.046$ & $\begin{array}{c}1.6 \pm 1.536 \\
2.125 \mathbf{( 0 . 0 2 8 )}\end{array}$ & $\begin{array}{c}4.0 \pm 2.596 \\
3.669(\mathbf{0 . 0 0 1})\end{array}$ & $\begin{array}{c}5.9 \pm 2.198 \\
3.863 \mathbf{( 0 . 0 0 1 )}\end{array}$ \\
\hline \multirow{2}{*}{$\begin{array}{l}\text { Bi-nuclea- } \\
\text { tion }\end{array}$} & $\mathbf{N}$ & $\begin{array}{c}\text { Mean } \pm \text { S.D. } \\
Z(p)\end{array}$ & $3.3 \pm 2.452$ & $\begin{array}{c}5.9 \pm 3.754 \\
2.606(\mathbf{0 . 0 0 9})\end{array}$ & $\begin{array}{c}15.8 \pm 5.307 \\
3.894(\mathbf{0 . 0 0 1})\end{array}$ & $\begin{array}{c}27.0 \pm 6.633 \\
3.924(\mathbf{0 . 0 0 1})\end{array}$ \\
\hline & $\mathbf{L}$ & $\begin{array}{c}\text { Mean } \pm \text { S.D. } \\
Z(p)\end{array}$ & $3.2 \pm 2.546$ & $\begin{array}{c}6.8 \pm 5.043 \\
2.690(\mathbf{0 . 0 0 7}) \\
\end{array}$ & $\begin{array}{c}18.6 \pm 5.915 \\
3.927(\mathbf{0 . 0 0 1 )} \\
\end{array}$ & $\begin{array}{c}29.4 \pm 6.056 \\
3.927(\mathbf{0 . 0 0 1 )} \\
\end{array}$ \\
\hline \multirow{2}{*}{$\begin{array}{l}\text { Multi-nu- } \\
\text { cleation }\end{array}$} & $\mathbf{N}$ & $\begin{array}{c}\text { Mean } \pm \text { S.D. } \\
Z(p)\end{array}$ & $0.1 \pm 0.447$ & $\begin{array}{c}0.2 \pm 0.616 \\
1.000(0.314)\end{array}$ & $\begin{array}{c}0.4 \pm 1.046 \\
1.134(0.257)\end{array}$ & $\begin{array}{c}0.9 \pm 1.651 \\
1.960(\mathbf{0 . 0 5})\end{array}$ \\
\hline & $\mathbf{L}$ & $\begin{array}{c}\text { Mean } \pm \text { S.D. } \\
Z(\mathrm{p})\end{array}$ & $0.1 \pm 0.447$ & $\begin{array}{c}0.2 \pm 0.894 \\
0.447(0.655)\end{array}$ & $\begin{array}{c}0.9 \pm 1.210 \\
2.309(\mathbf{0 . 0 2 1})\end{array}$ & $\begin{array}{c}1.2 \pm 1.642 \\
2.598(\mathbf{0 . 0 0 9})\end{array}$ \\
\hline \multirow{2}{*}{ ANC } & $\mathbf{N}$ & $\begin{array}{c}\text { Mean } \pm \text { S.D. } \\
Z(p)\end{array}$ & $4.7 \pm 3.511$ & $\begin{array}{c}10.4 \pm 5.897 \\
3.280(\mathbf{0 . 0 0 1})\end{array}$ & $\begin{array}{c}30.5 \pm 7.193 \\
3.929(\mathbf{0 . 0 0 1})\end{array}$ & $\begin{array}{c}52.4 \pm 11.10 \\
3.924 \mathbf{( 0 . 0 0 1 )}\end{array}$ \\
\hline & $\mathbf{L}$ & $\begin{array}{c}\text { Mean } \pm \text { S.D. } \\
Z(p)\end{array}$ & $5.5 \pm 3.171$ & $\begin{array}{c}14.8 \pm 8.167 \\
3.712(\mathbf{0 . 0 0 1 )}\end{array}$ & $\begin{array}{c}38.3 \pm 8.007 \\
3.924 \mathbf{( 0 . 0 0 1 )}\end{array}$ & $\begin{array}{c}59.2 \pm 9.070 \\
3.926(\mathbf{0 . 0 0 1})\end{array}$ \\
\hline
\end{tabular}

Table 1. Mean counts of various nuclear abnormalities at different radiation doses from baseline to $24 \mathrm{~Gy}(N=N o r m a l$ buccal mucosa; $L=$ Lesion; S.D. = Standard Deviation; $Z=$ Wilcoxon signed rank sum test; $p<0.05$ - Significant)

\section{Results}

No statistically significant differences were observed in the counts obtained by the two techniques used hence only the values obtained by fluorescent technique were considered for interpretation of the findings of the study in this paper. All the nuclear abnormalities that were studied i.e. micronucleation, nuclear budding, binucleation, and multinucleation, showed a dose dependent increase in response to radiation (Table 1, Fig 3a). The mean increase in the counts of these parameters was calculated by taking the difference between the values at 24 Gy and pretreatment value (Table 2).

Micronucleation: an increase in the counts of cells showing micronucleation was observed with increasing radiation dose. The frequency of micronucleated cells increased from a baseline value of $0.9 / 1000$ cells to $19.2 / 1000$ cells on the normal side and from $1.8 / 1000$ cells to $22.6 / 1000$ cells on the lesional side. The mean increase on the normal and lesional sides was 18.3 and 20.3 per thousand cells respectively. This increase was statistically significant $(p=0.001)$.

Nuclear budding: cells showing nuclear budding also increased significantly $(p=0.001)$ from their baseline counts of 0.6 and 0.4 per thousand cells on the normal

\begin{tabular}{|c|c|c|c|}
\hline Parameter & Site & \multirow{2}{*}{$\begin{array}{l}\text { Increase in } \\
\text { counts from } \\
\text { baseline to } \\
24 \mathrm{~Gy}\end{array}$} & \multirow{2}{*}{$\begin{array}{c}Z \\
(\mathbf{P})\end{array}$} \\
\hline & & & \\
\hline \multirow{2}{*}{ Micro-nucleus } & $\mathbf{N}$ & 18.3 & \multirow{2}{*}{$\begin{array}{r}1.9070 \\
(\mathbf{0 . 0 4 9 )}\end{array}$} \\
\hline & $\mathbf{L}$ & 20.8 & \\
\hline \multirow{2}{*}{ Nuclear budding } & $\mathbf{N}$ & 4.4 & \multirow{2}{*}{$\begin{array}{r}1.936 \\
(\mathbf{0 . 0 5})\end{array}$} \\
\hline & $\mathbf{L}$ & 5.5 & \\
\hline \multirow{2}{*}{ Bi-nucleation } & $\mathbf{N}$ & 23.7 & \multirow{2}{*}{$\begin{array}{c}0.97900 \\
\mathbf{( 0 . 3 2 8 )}\end{array}$} \\
\hline & $\mathbf{L}$ & 26.2 & \\
\hline \multirow{2}{*}{ Multi-nucleation } & $\mathbf{N}$ & 0.8 & \multirow{2}{*}{$\begin{array}{c}0.80000 \\
\mathbf{( 0 . 4 2 4 )}\end{array}$} \\
\hline & $\mathbf{L}$ & 1.1 & \\
\hline \multirow{2}{*}{ ANC } & $\mathbf{N}$ & 47.7 & \multirow{2}{*}{$\begin{array}{c}2.14400 \\
(\mathbf{0 . 0 3 2})\end{array}$} \\
\hline & $\mathbf{L}$ & 53.7 & \\
\hline
\end{tabular}

Table 2. Comparison of increase in counts of various nuclear parameters from baseline to 24 Gy radiation between normal and lesional side. $(N=$ Normal buccal mucosa; $L=$ Lesion $;=$ Mann Whiteney 'U'test; $p<0.05$ - Significant) e196 
and lesional side respectively to 5.0 and 5.9 per thousand cells at $24 \mathrm{~Gy}$. The mean increase was 4.4 and 5.5 per thousand cells on the normal and lesional side respectively.

Binucleation: counts of binucleated cells increased from the baseline values of 3.3 and 3.4 per thousand cells on the normal and lesional sides respectively to 27.0 and 29.2 per thousand cells at $24 \mathrm{~Gy}$. The mean increase was 23.7 and 26.2 per thousand cells which was statistically significant $(p=0.001)$.

Multinucleation: multinucleated cells increased significantly from 0.1 per thousand cells to 0.9 at $24 \mathrm{~Gy}$ $(p=0.05)$ on the normal side and from 0.1 per thousand to 1.2 at $24 \mathrm{~Gy}(p=0.01)$ on lesional side. The mean increase was 0.8 and 1.1 per thousand cells on normal and lesional side respectively.

$A N C$ : counts of abnormally nucleated cells increased significantly $(p=0.001)$ from pretreatment values of 4.7 and 5.5 per thousand cells on the normal and lesional sides respectively to 52.4 and 59.2 per thousand cells at 24 Gy. The mean increase was 47.7 and 53.7 per thousand cells respectively.

It was observed that the counts of all nuclear abnormalities were higher on the lesional side at all fractions and so were the increase in counts from the baseline value to 24 Gy (Table $1 \& 2$ ). When comparison between mean increase in counts on the lesional side to those on the normal side was made using Mann-Whitney "U" test, a statistically significant difference was observed in the counts of micronucleation $(p=0.049)$, nuclear budding $(p=0.05)$, and ANC $(p=0.032)$ while increase in the counts of binucleation and multinucleation were not significantly different between the two sites (Table 2).

No statistically significant correlation could be found between the increase in counts of any nuclear abnormality with tumor response (Table 3 ) but a trend was observed with all nuclear anomalies, except multinucleation, showing tendency for greater increase in those patients having a better tumor response (Fig $3 b$ ).

\section{Discussion}

Radiation as a modality for treatment of malignancies has been used for over a century now. Along with surgery it forms one of the mainstays in the management of OSCC. (1) Reaction of malignant cells as well as the surrounding oral tissues to radiotherapy depends on their radiosensitivity, but the variability in host-tumor response makes it difficult to assess and predict the outcome of such treatment in an individual patient. Radiation exerts its effect on both normal as well as malignant cells mainly by causing chromosomal injury, the endpoint of which can be detected by the frequency of micronucleus in dividing cells. Micronuclei are acentric fragments of a chromosome that lag during cell division and are not incorporated in the main nucleus. These are formed due to genotoxic damage to the cell e.g. radiation induced chromosomal injury and represent a lethal genomic injury that may play an important role in killing of tumor cells by ionizing radiations. The micronucleus test in peripheral blood lymphocytes and epithelial cells has been extensively used for monitoring genotoxic damage, caused by chemicals(14) and ionizing radiations(15), as well as the effectiveness of chemopreventive agents used against cancer(16). Micronucleus assay in cultured lymphocytes by the cytokinesis block method is recommended as a biologic dosimeter for radiation exposure. (12)

Apart from micronucleation other nuclear changes like nuclear budding, binucleation, and multinucleation have also been reported as effects of radiation.(5) Nuclear budding is thought to represent a micronucleus which has been overlapped by the main nucleus or incompletely expelled during karryokinesis and thus remains contiguous with the main nucleus. It may also represent direct effect of radiation on the nuclear membrane leading to nuclear blebing.(5) Radiation may also cause damage to pericetreolar matrix leading to multipolar mitosis which can result in formation of a multinucleated cell. Radiation induced peroxidation of membrane lipids can cause

\begin{tabular}{|c|c|c|c|c|c|c|}
\hline \multirow{2}{*}{$\begin{array}{c}\text { Tumor } \\
\text { Response }\end{array}$} & \multirow{2}{*}{$\mathbf{N}$} & Micronucleus & $\begin{array}{c}\text { Nuclear bu- } \\
\text { dding }\end{array}$ & Binucleation & Multinucleation & ANC \\
\cline { 3 - 7 } & & \multicolumn{5}{|c|}{ Mean (S.D) } \\
\hline Good & 8 & $22.00(1.85)$ & $7.00(5.45)$ & $25.00(5.35)$ & $1.25(1.49)$ & $55.25(3.99)$ \\
Partial & 7 & $20.57(2.51)$ & $6.00(4.32)$ & $23.43(3.96)$ & $\begin{array}{l}1.14(1.95) \\
2.00(1.41)\end{array}$ & $50.86(10.06)$ \\
Poor & 5 & $20.40(4.56)$ & $5.60(2.19)$ & $22.00(4.24)$ & $2.00(4.69)$ \\
\hline H (p) & & $1.11(0.57)$ & $0.02(0.99)$ & $1.24(0.54)$ & $0.97(0.62)$ & $2.44(0.30)$ \\
\hline
\end{tabular}

Table 3. Correlation between mean increase in nuclear abnormalities in lesional smears with tumor response $(N=$ No. of cases; S.D. $=$ Standard Deviation; $H=$ Kruskal-Wallis test; $p<0.05$ - Significant) 
damage to cell membrane which may result in failure of cytoplasmic division after nuclear division has taken place leading to formation of a binucleated cell. Further division in such a cell would lead to multinucleation.(5) Radiation induced nuclear damage will ultimately lead to clonogenic cell death i.e. the cell will be rendered incapable of producing a progeny, and hence proliferation of that clone is inhibited. Thus the cell undergoes a functional or reproductive death though it may be physically alive for some time.

The results of our study show a dose related change in all the nuclear parameters that were studied i.e. micronucleation, nuclear budding, binucleation, and multinucleation. These findings are consistent with previous studies where a similar dose related increase in nuclear abnormalities has been reported.(5-11)

Another finding which is evident in the present study is a non-linear increase in the counts of nuclear abnormalities on exposure to increasing doses of radiation. It can be observed from the graphs (Fig. 3a) that the elevation in the frequencies of the various nuclear abnormalities follows a gentle curve up till 8 Gy but after that the rise is comparatively much steeper. A similar "hockey stick" curve for induction of micronuclei in lymphocytes exposed to ionizing radiation has been previously reported and may result from DNA repair processes taking place at low radiation doses leading to rejoining of DNA strand breaks during the $\mathrm{S}$ phase of cell cycle before the cell enters the mitotic phase.(17) With an increase in the radiation dose the repair capacity of the cell will decrease while the amount of chromosomal damage will increase leading to accumulation of unrepaired DNA fragments which will lead to formation of more numbers of micronuclei and nuclear buddings. A similar accumulation of unrepaired damage to the cell membrane at higher doses of radiation will lead to an increase in the counts of binucleated and multinucleated cells too.

The micronuclei counts were found to increase steadily with increasing doses of radiation. A dose-response relationship between the counts of micronucleated cells and radiation has previously been reported both in vitro and in vivo(18) as well as in OSCC patients receiving radiation therapy.(5-11) Hence the results of this study support the view that micronucleus is a sensitive indicator of chromosomal damage caused by ionizing radiation. A rise in the count of cells showing nuclear budding was also seen with increasing radiation dosage but this increase was more significant only after dose of $16 \mathrm{~Gy}$. Lack of significant increase in nuclear budding during initial phase of the treatment can also be explained by efficient DNA repair at low doses of radiation as stated above.

The count of binucleated cells also increased with increasing radiation exposure, which is in agreement with previous studies. Binucleation is not thought to be cau- sed by a direct effect of radiation on the nucleus rather it may represent damage to cell membrane due to radiation induced peroxidation of membrane lipids leading to inability of the cell to undergo cytokinesis.(9) A binucleated cell may also be formed by certain non radiation-induced mechanisms, and it may represent a mitotic cell which has not undergone cytokinesis as yet. $(5,9)$ A substantially higher count of binucleated cells in the pretreatment smears in comparison to other nuclear abnormalities, as observed in the present study, supports the hypothesis that a subset of these cells may be formed by certain other non radiation induced mechanisms. This is also supported by the fact that binulceated cells have also been reported in smears from normal oral mucosa of healthy controls as well as OSCC patients without any genotoxic exposure.(19) In the present study high counts of binucleated cells, as compared to other nuclear abnormalities, is seen at all levels of radiation exposure. This population of binucleated cells may be composed of two subpopulations. A proportion of these binucleated cells will represent lethal radiation injury, where as some may represent undamaged dividing cells, as tissues are known to repopulate after exposure to fractionated radiation. As in a smear it is impossible to differentiate between binucleated cells formed due to radiation injury from those formed by other non radiation-induced mechanisms, the significance of binucleation as an indicator of radiation damage in oral smears remains unresolved.

Two mechanisms of radiation induced multinucleation have been proposed. Cell membrane damage can lead to binucleation as discussed above and a further division in one or both of the nuclei in a binucleated cell will lead to multinucleation. Another proposed mechanism is due to radiation induced damage to pericentriolar matrix leading to multipolar mitosis.(9) In the present study although a net increase in the count of multinucleated cells is seen, it is significant only at 24Gy (Table 1). Also the counts of multinucleated cells were lower than the counts of other nuclear abnormalities at all doses. Previous studies have reported higher count of multinucleated cells than that observed in our study.(9) One of the reasons for low counts of multinucleated cells in our observations may be due to the fact that in the present study the slides were scored at 100X magnification, which might have resulted in discounting of a number of these cells as overlaps that may have appeared to be multinucleated at 40X magnification used in previous studies. Hence the relationship of multinucleation with radiation needs further investigation.

A comparison between the counts of various radiationinduced nuclear abnormalities, at similar radiation doses, among different studies revealed a marked variation in the frequency of these parameters.(5-11) A large inter laboratory variability has been observed in scoring of micronucleus frequency in an extensive study perfor- 
med to address this issue.(20) It was suggested that interpretation of scoring criteria ultimately depends on the subjective evaluation of each scorer and laboratory, so that some laboratories may be more cautious in accepting a cell showing micronucleation than others. Another practical limitation may be the quality of the optics of microscope used. Also it has been suggested that the scorer's experience plays an important role in scoring the cells.(20) Similar inter-laboratory variations may also be seen in case of other radiation induced nuclear changes. In light of this large inter-laboratory variability comparisons of data from different studies may not be very accurate. We suggest that strict criteria to evaluate these parameters need to be established before using them as an assay for radiosensitivity prediction.

A marked inter-individual variation in the baseline frequencies of micronucleus has been reported which has been a cause of concern in utilizing this assay as an indicator of genotoxic exposure. $(21,22)$ This may also hold good for other nuclear anomalies too. Thus the count of these parameters at any given dose of radiation may be influenced by their baseline frequencies. In the present study, the mean increase in the counts of various parameters was calculated by computing the difference in the baseline frequencies and the counts at 24 Gy (Table 2). This mean increase in the count has been used for various comparisons based on the premise that this may be a better representation of radiation-induced damage as compared to the absolute counts of these parameters at $24 \mathrm{~Gy}$. It has been advocated that for studying genotoxic exposure using the micronucleus assay, the study subjects can themselves act as controls.(23)

It was observed that the counts of nuclear anomalies was higher in the lesional smears, as compared to those collected from normal buccal mucosa, at all doses of radiation (Table 1). Also the mean increase in the counts of nuclear abnormalities was higher in the lesional smears (Table 2). This can be explained by the fact that radiation exerts its lethal effect during the time of cell division and as the studied parameters represent endpoints of mitotic cell death, their counts are higher in tumor cells which have a higher proliferative activity as compared to the cells from normal mucosa. Another reason for this difference in the counts in lesional and normal smears may be explained by the difference in the cell kinetics between the normal and tumor tissue. Cells have been shown to vary in radiosensitivity at different phases of cell cycle. (24) Because a cell population at any given time is asynchronous in relation to cell cycle, the radiosensitivity of the cells also varies i.e. some cells may be in a more radiosensitive phase than others. After exposure to a dose of radiation the surviving cells in an initially asynchronous population will partially become synchronized in a relatively radioresistant phase of cell cycle, because of preferential killing of cells in radiosensitive phases. Pro- liferating cells, particularly tumor cells, show a wide variation in the rates at which they move from one mitotic phase to the next when compared to normal cells which do not show marked variation. These large variations in proliferation rates ensure an early redistribution of tumor cells to sensitive phases before the next radiation exposure. Such redistribution produces a net "self sensitization" which does not occur in non-proliferating cell population. Thus fractionation of dose enhances the therapeutic ratio by permitting division cycle redistribution among surviving tumor cells but not in late responding normal tissue. Hence a larger number of tumor cells are killed at every fraction as compared to normal tissue. (25) Even though all nuclear abnormalities increased to a greater extent in the lesional smear this difference was statistically significant only for miconucleation and nuclear budding showing them to be more sensitive indicators for radiation damage. Previous studies have also shown these two to be superior markers to other parameters in assessing radiation induced cellular changes.(10) It was also observed from the results that a combination of these nuclear anomalies (taken as a separate parameter) may have a greater sensitivity for assessing radiation induced changes (Table 2). Since all these parameters are indicators of clonigenic cell death their combined count will naturally be expected to be a better indicator of the final outcome than any one of them alone.

Our data failed to show a statistically significant correlation between the counts of nuclear abnormalities and tumor response but a definite trend was observed with all nuclear parameters, except multinucleation, showing greater increase in counts in patients having better tumor response (Fig. 3b, Table 3). One of the reasons for the lack of such correlation in our study could be due to a small sample size as well as a short follow-up period. Another limitation of the present study is that the study group was diverse and consisted of patients in various stages of the disease. The support for reliability of micronucleus assay in prediction of radioresponse has been equivocal. Though some studies show a positive correlation between the micronucleus counts and tumor radiosensitivity $(6,7)$, others have failed to find any such correlation.(26-28) Emphasis has been given to the role of other mechanisms of cell death, e.g. radiation-induced apoptosis, in conjunction with mitotic cell death in determining tumor radiosensitivity.(28) In fact radiationinduced apoptosis has been shown to affect the correlation between micronucleus formation and cell survival. $(29,30)$ Cell lines producing low levels of micronuclei have been found to be more susceptible to radiation induced apoptosis, suggesting that assessment of both mechanisms of cell killing may be required to predict cell survival.(30)

To conclude, the results of the present study show that a direct dose-response relationship between the fre- 
quencies of various nuclear abnormalities and radiation exists in oral squamous cell carcinoma, as assessed by studying sequential smears from patients undergoing fractionated radiotherapy. Micronucleation and nuclear budding appear to be the most reliable markers for radiation damage among all anomalies. The study does not show a direct statistically significant correlation between the frequencies of nuclear abnormalities with primary tumor response though a trend towards higher counts in more radiosensitive tumors is seen. There is a need for further studies with larger sample size, well defined patient cohorts, and longer follow-up to improve the understanding of the role of these changes in predicting tumor radiosensitivity.

\section{References}

1. Zheng JW, Qiu WL, Zhang ZY. Combined and sequential treatment of oral and maxillofacial malignancies: an evolving concept and clinical protocol. Chin Med J (Engl). 2008;121:1945-52.

2. Graham RM. The effect of radiation on vaginal cells in cervical carcinoma; description of cellular changes. Surg Gynecol Obstet. 1947;84:153-65.

3. Sliverman S Jr, Sheline GE, Gillooly CJ Jr. Radiation therapy and oral carcinoma. Radiation response and exfoliative cytology. Cancer. 1967;20:1297-300.

4. Umiker WO. Neucleoprotein patterns of irradiated malignant squamous cells in oral smears. Am J Clin Pathol. 1958;30:514-8.

5. Bhattathiri NV, Bindu L, Remani P, Chandralekha B, Nair KM. Radiation-induced acute immediate nuclear abnormalities in oral cancer cells: serial cytologic evaluation. Acta Cytol. 1998;42:108490.

6. Bhattathiri NV, Bharathykkutty C, Prathapan R, Chirayathmanjiyil DA, Nair KM. Prediction of radiosensitivity of oral cancers by serial cytological assay of nuclear changes. Radiother Oncol. 1998;49:61-5.

7. Bindu L, Balaram P, Mathew A, Remani P, Bhattathiri VN, Nair MK. Radiation-induced changes in oral carcinoma cells-a multiparametric evaluation. Cytopathology. 2003;14:287-93.

8. Mehrotra R, Goel N, Singh M, Kumar D. Radiation-related cytological changes in oral malignant cells. Indian J Pathol Microbiol. 2004;47:343-7.

9. Mehrotra R, Madhu, Singh M. Serial scrape smear cytology of radiation response in normal and malignant cells of oral cavity. Indian J Pathol Microbiol. 2004;47:497-502.

10. Sharma P, Kumar N, Bahadur AK, Shukla DK. Quantitative analysis of radiation-associated cellular changes in oral cancer and their correlations with histologic grade and clinical stage: a multivariate evaluation of 43 patients. Anal Quant Cytol Histol. 2005;27:111-7.

11. Kumari R, Chaugule A, Goyal PK. Karyoanomalic frequency during radiotherapy. J Cancer Res Ther. 2005;1:187-90.

12. Balasem AN, Ali AS. Establishment of dose response relationship between doses of Cs-137 gamma-rays and frequencies of micronuclei in human peripheral blood lymphocytes. Mutat Res. 1991;259:133-8.

13. Shibamoto Y, Streffer C, Fuhrmann C, Budach V. Tumor radiosensitivity prediction by cytokinesis-block micronucleus assay. Radiat Res. 1991;128:293-300.

14. Sarto F, Tomanin R, Giacomelli L, Iannini G, Cuppiraggi AR. The micronucleus assay in human exfoliated cells of nose and mouth: application to occupational exposure to chromic acid and ethylene oxide. Mutat Res. 1990;244:345-51.

15. Kormos C, Koteles GJ. Micronuclei in X-irradiated human lymphocytes. Mutat Res. 1988;199:31-5.

16. Benner SE, Lippman SM, Wargovich MJ, Lee JJ, Velasco M, Mar- tin JW, et al. Micronuclei, a biomarker for chemopreventive trials: results of a randomized study in oral pre-malignancy. Int J Cancer. 1994;59:457-9.

17. Mitchell JC, Norman A. The induction of micronuclei in human lymphocytes by low doses of radiation. Int J Radiat Biol Relat Stud Phys Chem Med. 1987;52:527-35.

18. Jagetia GC, Ganapathi NG. Radiation-induced micronucleus formation in mouse bone marrow after low dose exposure. Mutat Res. 1994;304:235-42.

19. Ramirez A, Saldanha PH. Micronucleus investigation of alcoholic patients with oral carcinomas. Genet Mol Res. 2002;1:246-60.

20. Fenech M, Bonassi S, Turner J, Lando C, Ceppi M, Chang WP, et al; HUman MicroNucleus project. Intra- and inter-laboratory variation in the scoring of micronuclei and nucleoplasmic bridges in binucleated human lymphocytes. Results of an international slidescoring exercise by the HUMN project. Mutat Res. 2003;534:4564. Erratum in: Mutat Res. 2003;538:185-6.

21. Huber R, Braselmann H, Bauchinger M. Intra- and inter-individual variation of background and radiation-induced micronucleus frequencies in human lymphocytes. Int J Radiat Biol 1992;61:65561.

22. Ganguly BB. Cell division, chromosomal damage and micronucleus formation in peripheral lymphocytes of healthy donors: related to donors age. Mutat Res 1993;295:135-48.

23. Peace BE, Succop P. Spontaneous micronucleus frequency and age: what are the normal values? Mutat Res 1999;425:225-30.

24. Pawlik TM, Keyomarsi K. Role of cell cycle in mediating sensitivity to radiotherapy. Int J Radiat Oncol Biol Phys. 2004;59:928-42.

25. Whithers HR. Cell cycle redistribution as a factor in multifraction irradiation. Radiology. 1975;114:199-202.

26. Villa R, Zaffaroni N, Gornati D, Costa A, Silvestrini R. Lack of correlation between micronucleus formation and radiosensitivity in established and primary cultures of human tumors. Br J Cancer. 1994,70:1112-7.

27. Bush C, McMillan TJ. Micronucleus formation in human tumor cells: lack of correlation with radiosensitivity. Br J Cancer. 1993;67:102-6.

28. Akudugu JM, Slabbert JP, Serafin A, Bohm L. Frequency of radiation induced micronuclei in neuronal cells does not correlate with clonogenic survival. Radiat Res. 2000;153:62-7. Erratum in: Radiat Res 2000;153:609.

29. Abend M, Rhein A, Gilbert KP, Blakely WF, van Beuningen D. Correlation of micronucleus and apoptosis assays with reproductive cell death. Int J Radiat Biol 1995;67:315-26.

30. Guo GZ, Sasai K, Oya N, Takagi T, Shibuya K, Hiraoka M. Simultaneous evaluation of radiation-induced apoptosis and micronuclei in five cell lines. Int J Radiat Biol 1998;73:297-302. 